\title{
Research on Electricity Demand Combination Forecasting Model in Beijing-Tianjin-Hebei Region Based on Shapley Value
}

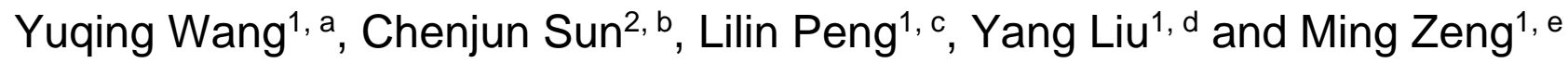 \\ ${ }^{1}$ School of North China Electric Power University, Beijing, 102206, China; \\ ${ }^{2}$ State Grid Hebei Electric Power Company, Shijiazhuang, 050000, China. \\ a594842366.qq.com, bscj@he.sgcc.com.cn, 'penglilinbj@126.com, dliuyang3983@126.com, \\ e921735063@qq.com
}

\begin{abstract}
Due to the electricity power is the foundation of economic development, reasonable and accurate electricity demand forecasting not only helps to develop electricity power planning scientifically, but also has important reference value to the economic development planning. In order to integrate different forecast models' strengths as well as improve the forecast accuracy, this paper puts forward the electricity demand forecasting model based on Shapley value. First, it chooses one-dimensional linear regression model, Holt two-parameter linear exponential smoothing model and ARIMA model for electricity demand forecasting respectively, and through the game theory Shapley value theory determines the weight of single model in the portfolio model, and then the combined forecasting result is obtained; Second, it analyzes the electricity demand data in Beijing-Tianjin-Hebei Region and the results show that the proposed method has high forecast accuracy; Finally, it forecasts electricity demand in Beijing-Tianjin-Hebei Region during "13th five-year" period and provides decision-making basis for the economic development planning of Beijing, Tianjin Hebei province during "13th five-year" period.
\end{abstract}

Keywords: Shapley value; Combined model; Electricity demand forecasting.

\section{Introduction}

President Xi Jinping put forward Beijing-Tianjin-Hebei Region coordinated development strategy on February 26, 2014 and the Beijing-Tianjin-Hebei Region integration has become one of the top macro strategies in the domestic development. As the electricity is the foundation of economic development and the electricity demand and economic growth interact with each other [1-3], electricity demand forecasting is of great significance for the rapid development of Beijing-Tianjin-Hebei Region during "13th five-year" period. Currently, tens of kinds electricity demand forecasting methods have been proposed at home and abroad, such as exponential smoothing method, trend analysis method, curve fitting method, the moving average method, artificial neural networks method, linear regression analysis method and gray forecast method, system kinetic method and so on. These methods have their advantages and disadvantages while the forecasting results are different [4]. Combined forecasting can integrate the strengths of different models to make up for weaknesses, and the various forecasts are considered in combination to enhance the forecasting reliability as well as improve the forecasting accuracy of the results.

This paper combines one-dimensional linear regression model, Holt two-parameter linear exponential smoothing model and the ARIMA model, and determines the weight of each forecast model by applying Shapley value weight allocation method, to build electricity demand combined forecasting model based on Shapley value, and conducts electricity demand forecasting in Beijing-Tianjin-Hebei Region during "13th five-year" period.

\section{Electricity demand combination forecasting model based on Shapley value}

\subsection{Principle of Combination Forecasting}

Different individual forecast method excavates the deep information of the research object from different angles. If using only one forecasting method may result in partial loss of useful information 
[5]. No matter forecasting accuracy big or small, each single forecasting includes independent information of the system. If only considering a certain model can cause the waste of information, and if different forecasting methods used together can improve the forecast performance of the system. Electricity demand forecasting, therefore, should be according to its basic requirements and application characteristics of different forecasting models, and chooses better several adaptive forecasting models to predict respectively and then take a weighted average with the forecasting results in order to get the final forecasting value, which is shown as formula (1) :

$$
Y_{t}=\sum_{i=1}^{3} \lambda_{i} Y_{i t}
$$

Wherein, $\sum_{i=1}^{3} \lambda_{i}=1, Y_{t}$ are the forecasting value, $Y_{i t}$ is the forecasting value of the model $i, \lambda_{i}$ is weight of the model $i$.

The average of forecasting error absolute value of the model $i$ is:

$$
E_{i}=\frac{1}{m} \sum_{j=1}^{3}\left|e_{i j}\right| \quad(i=1,2,3)
$$

Where, $m$ is the specific number of samples; $e_{i j}$ is the residual of data $j$ in forecasting model $i$.

The total average forecasting error of a single model forecasting the average absolute error is shown in the following formula:

$$
E=\frac{1}{3} \sum_{i=1}^{3} E_{i} \quad(i=1,2,3)
$$

\subsection{Weight calculation method based on Shapley value}

Shapley value method is a mathematical method used to solve the problem of multiple-person cooperation game [6-7]. It is mainly used for measuring the size of contribution of each member in a cooperation team, reflecting the role and importance of each member in the cooperation. The biggest advantage of Shapley value method is that its principles and results are very fair for the cooperation parties, so that it is easy to be accepted from each partner. Therefore, this paper uses Shapley value weight allocation method to determine the weight of each forecasting model [8].

Introduce Shapley theory belonging to the game theory, and consider errors of single forecasting model as returns of the model, then the total errors of combination forecasting model is seen as the common benefit of each forecasting model. Therefore, the models in fact constitute a kind of partnership each other. Regard the total combination forecasting errors $E$ as total benefits and allocate it to single forecasting model according to Shapley value theory. So that it determines the weight of single forecasting model in the combination forecasting model. Shapley value error distribution formula is:

$$
E_{i}^{\prime}=\sum_{\{s \mid i \in s\}} w(|s|)[E(s)-E(s-\{i\})]
$$

Where, $w(|s|)=\frac{(n-|s|) !(|s|-1) !}{n !}, E_{i}^{\prime}$ is the Shapley value of forecasting model $i$, namely the share of errors (income) amount of the model; $S$ refers to a set of all models including model $i$; $|S|$ is the number of forecasting models; $|s|=3$; refer to remove model $i$ from all the models; $E(s)$ is the error amount with all models participating, $E(s-\{i\})$ is the error amount after removing the model $i$ from all models. Finally, the formula of weights is as follows:

$$
\lambda_{i}=\frac{1}{n-1} \cdot \frac{E-E_{i}^{\prime}}{E} \quad(i=1,2,3 ; n=3)
$$




\section{Single model selection}

\subsection{Simple linear regression model}

Simple linear regression model is the most widely adaptable method in a variety of forecasting methods, and the error levels among different types of forecasting are unlikely, and the forecasting results are more suitable for part of basic value, especially in the case of adequate historical data.

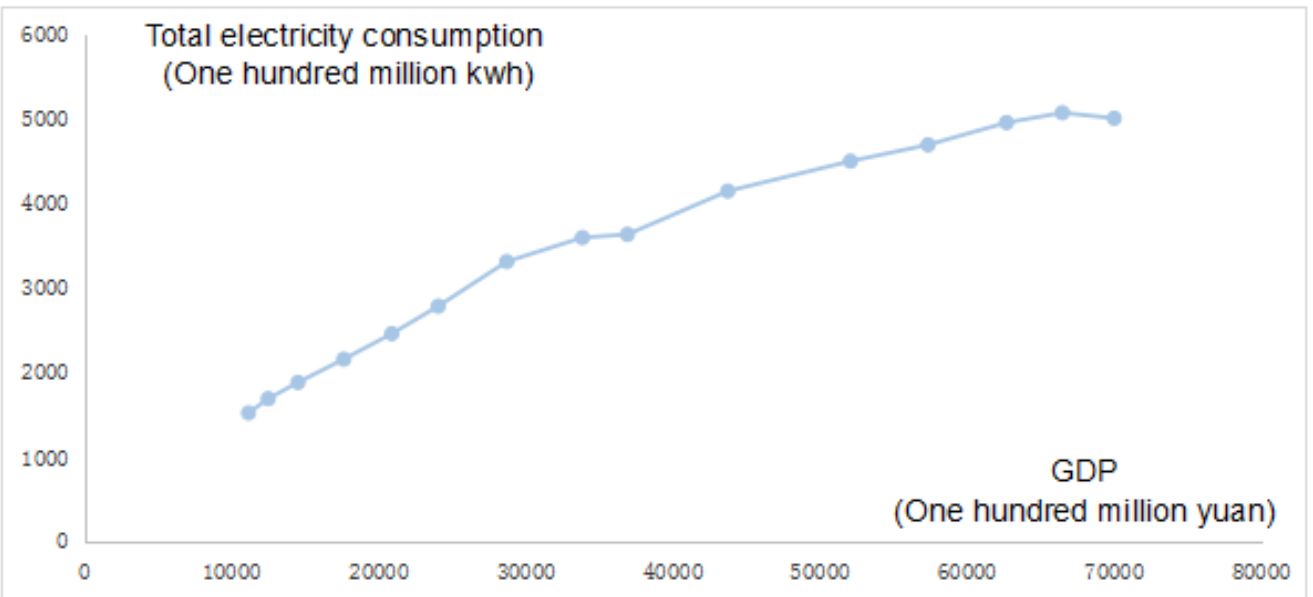

Fig. 1 The total electricity consumption curve of Beijing-Tianjin-Hebei Region in 2000-2015

\subsection{Holt double parameter linear exponential smoothing model}

Exponential smoothing, on the basis of moving average, constructs forecasting models by calculating the smoothing values of indexes whose basic idea is obtaining forecasting value according to the weighted sum of the historical observations. Determining the weight is related with time, namely weights of new data are large and weights of old data are small, which is compatible with the data of various periods. Depending on the form of the original data series, exponential smoothing can be divided into single exponential smoothing, double exponential smoothing and cubic exponential smoothing, where double exponential smoothing is applied more widely in electricity forecasting. Therefore, choose Holt double parameter linear exponential smoothing model as the second one in combination forecasting models.

\subsection{ARIMA model}

ARIMA model is suitable to describe non-stationary random process, which is on the basis of ARMA model with describing stationary random process using differential operator able to make trend time series $Y_{t}$ convert into stationary random time series. Change in electricity demand is a non-stationary random process coming with certain growth trend and periodicity, therefore, this paper selects ARIMA model as the third one in combination forecasting model.

\section{Numerical example}

In order to verify scientific and rationality of the proposed model, this section takes electricity demand in Beijing-Tianjin-Hebei Region as the example for analysis. Numerical example is divided into two parts, the first part is based on known data in 2,000-2010 to forecast electricity demand in 2011-2015 and check it with the actual results; Then, on the basis of ensuring the model scientific and rational, it forecasts electricity demand in "13th five-year" period (2016-2020) further.

\subsection{Historical Data}

According to "Beijing Statistical Yearbook 2015", "Tianjin Statistical Yearbook 2015" and "Hebei Economic Yearbook 2015", the total electricity consumption and GDP during 2000-2015 in Beijing, Tianjin, and Hebei province are shown in Table 1. 
Table 1 Total electricity consumption and GDP raw data in Beijing, Tianjin and Hebei province in 2000-2015

\begin{tabular}{ccc}
\hline Year & $\begin{array}{c}\text { Total electricity consumption } \\
\text { (One hundred million kwh) }\end{array}$ & $\begin{array}{c}\text { GDP } \\
\text { (One hundred million yuan) }\end{array}$ \\
\hline 2000 & 9907.54 & 9907.54 \\
2001 & 11143.85 & 11143.85 \\
2002 & 12484.04 & 12484.04 \\
2003 & 14506.52 & 14506.52 \\
2004 & 17621.8 & 17621.80 \\
2005 & 20887.25 & 20887.25 \\
2006 & 24048.14 & 24048.14 \\
2007 & 28706.88 & 28706.88 \\
2008 & 33845.98 & 33845.98 \\
2009 & 36910.33 & 36910.33 \\
2010 & 43732.32 & 43732.32 \\
2011 & 52074.94 & 52074.94 \\
2012 & 57348.28 & 57348.28 \\
2013 & 62685.82 & 62685.82 \\
2014 & 66478.76 & 66478.76 \\
2015 & 70006.1 & 70006.10 \\
\hline
\end{tabular}

4.2 Annual electricity demand forecast and error checking analysis during 2011-2015 in Beijing-Tianjin-Hebei Region

With known data of total electricity consumption and GDP in Beijing-Tianjin-Hebei Region during 2000-2010, apply single linear regression model, Holt two parameters linear exponential smoothing model and ARIMA model to respectively forecast electricity demand in in Beijing, Tianjin, and Hebei province during 2011-2015 and the results are as shown in table 2. According to the forecasting error of each model, apply Shapley value weight calculation method to determine the weight of each model in combination forecast, and the weights of single linear regression model, Holt two-parameter linear exponential smoothing model and ARIMA model are respectively 0.31,0.34 and 0.35 .

Forecast the electricity demand in Beijing-Tianjin-Hebei Region by combination forecasting model in 2011-2015 as well as contrast it with the actual value and calculate error rate and average error rate for each year, which are shown in table 2. As it can be seen from the table, average error rate of combination forecast based on Shapley less than 3\% is less than that of single model, in line with electricity demand forecasting and high accuracy. Therefore, it can be considered that the combination forecasting model proposed in this paper is available, which can provide references for future electricity demand forecasting in Beijing-Tianjin-Hebei Region.

Table 2 Model forecasting results and errors (one hundred million $\mathrm{kWh}$ )

\begin{tabular}{|c|c|c|c|c|c|c|c|c|c|}
\hline \multirow[b]{2}{*}{ Year } & \multirow[b]{2}{*}{$\begin{array}{l}\text { Actual } \\
\text { value }\end{array}$} & \multirow{2}{*}{$\begin{array}{c}\text { Forecasti } \\
\text { ng results } \\
\text { of single } \\
\text { linear } \\
\text { regressio } \\
\text { n model }\end{array}$} & \multirow{2}{*}{$\begin{array}{l}\text { Forecasti } \\
\text { ng results } \\
\text { of } \\
\text { Exponent } \\
\text { ial } \\
\text { smoothin } \\
\text { g model }\end{array}$} & \multirow{2}{*}{$\begin{array}{c}\text { Forecasti } \\
\text { ng results } \\
\text { of } \\
\text { ARIMA } \\
\text { model }\end{array}$} & \multirow{2}{*}{$\begin{array}{l}\text { Forecasti } \\
\text { ng results } \\
\text { of } \\
\text { combinati } \\
\text { on Model }\end{array}$} & \multicolumn{4}{|c|}{ Forecasting error } \\
\hline & & & & & & $\begin{array}{c}\text { Single } \\
\text { linear } \\
\text { regressio } \\
\text { n model }\end{array}$ & $\begin{array}{l}\text { Exponent } \\
\text { ial } \\
\text { smoothin } \\
\text { g model }\end{array}$ & $\begin{array}{c}\text { ARIMA } \\
\text { model }\end{array}$ & $\begin{array}{c}\text { Combinat } \\
\text { ion } \\
\text { Model }\end{array}$ \\
\hline 2011 & 4501.77 & 4393.81 & 4424.02 & 4385.83 & 4401.33 & $2.40 \%$ & $1.73 \%$ & $2.58 \%$ & $2.23 \%$ \\
\hline 2012 & 4695.17 & 4670.76 & 4778.72 & 4740.44 & 4731.99 & $0.52 \%$ & $1.78 \%$ & $0.96 \%$ & $0.78 \%$ \\
\hline 2013 & 4958.79 & 5001.68 & 4972.03 & 4933.84 & 4967.82 & $0.86 \%$ & $0.27 \%$ & $0.50 \%$ & $0.18 \%$ \\
\hline 2014 & 5075.09 & 5136.85 & 5235.63 & 5197.46 & 5191.78 & $1.22 \%$ & $3.16 \%$ & $2.41 \%$ & $2.30 \%$ \\
\hline 2015 & 5010.03 & 5455.54 & 5301.75 & 5313.76 & 5353.43 & $8.89 \%$ & $5.82 \%$ & $6.06 \%$ & $6.85 \%$ \\
\hline $\begin{array}{c}\text { Average } \\
\text { value }\end{array}$ & & & & & & $2.78 \%$ & $2.55 \%$ & $2.50 \%$ & $2.47 \%$ \\
\hline
\end{tabular}




\subsection{Electricity demand forecasting in Beijing-Tianjin-Hebei Region during "13th five-year" period}

According to "13th five Year Plan" in Beijing-Tianjin-Hebei Region, the average annual GDP growth targets of the three regions are respectively $6.5 \%, 8.5 \%$ and $7 \%$. Weight average the annual GDP of Beijing-Tianjin-Hebei Region by weight (in table 3) of the three regions for GDP average contribution rate in 2000-2015 and obtain the GDP growth target is 7.13\%. The result of forecasting GDP in Beijing-Tianjin-Hebei Region during 2016-2020 is shown in table 4.

Table 3 GDP contribution rates of Beijing-Tianjin-Hebei Region

\begin{tabular}{cccc}
\hline Year & Beijing & Tianjin & Hebei province \\
\hline 2000 & $31.91 \%$ & $17.18 \%$ & $50.91 \%$ \\
2001 & $33.27 \%$ & $17.22 \%$ & $49.50 \%$ \\
2002 & $34.56 \%$ & $17.23 \%$ & $48.21 \%$ \\
2003 & $34.52 \%$ & $17.77 \%$ & $47.71 \%$ \\
2004 & $34.24 \%$ & $17.65 \%$ & $48.11 \%$ \\
2005 & $33.37 \%$ & $18.70 \%$ & $47.93 \%$ \\
2006 & $33.76 \%$ & $18.56 \%$ & $47.69 \%$ \\
2007 & $34.30 \%$ & $18.30 \%$ & $47.40 \%$ \\
2008 & $32.84 \%$ & $19.85 \%$ & $47.31 \%$ \\
2009 & $32.93 \%$ & $20.38 \%$ & $46.70 \%$ \\
2010 & $32.27 \%$ & $21.09 \%$ & $46.63 \%$ \\
2011 & $31.21 \%$ & $21.71 \%$ & $47.08 \%$ \\
2012 & $31.18 \%$ & $22.48 \%$ & $46.34 \%$ \\
2013 & $31.59 \%$ & $23.04 \%$ & $45.37 \%$ \\
2014 & $32.09 \%$ & $23.66 \%$ & $44.26 \%$ \\
2015 & $32.85 \%$ & $24.57 \%$ & $42.58 \%$ \\
Average value & $32.93 \%$ & $19.96 \%$ & $47.11 \%$ \\
\hline
\end{tabular}

Forecast "13th five-Year" electricity demand according to the total electricity consumption data during 2000-2015 and GDP forecasting data during 2016-2020 in Beijing-Tianjin-Hebei Region, and the results are shown in Table 4, which shows that GDP in 2020 will increase $41.14 \%$ compared with 2015, electricity demand will increase $31.52 \%$ compared with 2015.

Table 4 Forecasting results of GDP and electricity demand in Beijing, Tianjin, and Hebei province during "13th five-year"

\begin{tabular}{ccc}
\hline Year & $\begin{array}{c}\text { Electricity demand } \\
\text { (One hundred million kwh) }\end{array}$ & $\begin{array}{c}\text { GDP } \\
\text { (One hundred million yuan) }\end{array}$ \\
\hline 2016 & 5421.60 & 75000.88 \\
2017 & 5701.92 & 80352.03 \\
2018 & 5989.57 & 86084.97 \\
2019 & 6285.08 & 92226.94 \\
2020 & 6589.02 & 98807.13 \\
\hline
\end{tabular}

\section{Summary}

This paper forecasts electricity demand in Beijing, Tianjin, and Hebei province with single linear regression, Holt double parameters linear exponential smoothing model and ARIMA model, applying Shapley value weight allocation method to determine the weight of single forecasting method weight, and builds electricity demand combination forecasting model based on Shapley value. By analyzing electricity demand forecasting numerical example in Beijing-Tianjin-Hebei Region, it verifies that forecasting accuracy of combination model is higher than that of each single prediction model, providing a very useful new method. Meanwhile, according to the electricity demand forecast results during "13th five-year" period in Beijing, Tianjin, Hebei province, the electricity demand will increase $31.52 \%$ compared with 2015. Therefore, the Government is supposed to take active measures to reduce enormous pressures on environment due to electricity demand growth. 


\section{Acknowledgments}

This work is supported by the Science and Technology Project of State Grid of China (Research on the effects of air pollution prevention and control on the power supply and demand of Beijing-Tianjin-Hebei Region).

\section{References}

[1] FAN Decheng, WANG Shaohua, ZHANG Wei. Research on Prediction of China's Electric Power Demand under Low-Carbon Economy Target [J]. Power System Technology. 2012, 36 (7): $19-25$.

[2] ZHANG Mingming. The Research on the Relationship between Electric Power Supply and Demand and Sustainable Economic Growth in China [D]. JiLin University. 2008.

[3] YANG Jie. Discussion the relationship between China's power and economic development and mid long term power load forecasting [D]. KunMing University of Science and Technology. 2007

[4] CHEN Yuxiang, ZHANG Hanya. Forecasting Technology and Application [M]. Beijing: Mechanical Industry Press, 1985.

[5] LI Na, LIU Shuyong, ZENG Ming2, LIU Lixia1, LI Yuanfei, HAN Xu. Energy Demand Forecasting Method Based on Shapley Value Theory [J]. Electric Power Construction, 2016, 37 (1): $15-22$.

[6] CHEN Huayou. A Kind of Cooperative Games Method Determining Weights of Combination Forecasting [J]. FORECASTING. 2003, 22 (1):75-77.

[7] LU Qi, GU Pei-liang, QIU Shiming. The Construction and Application of Combination Forecasting Model in Chinese Energy Consumption System [J]. Systems Engineering Theory and Practice2003, 23 (3): 24-30.

[8] HUANG Yi, ZHAO Guangzhou, WANG Yanwei. Research on the portfolio prediction methods of China energy consumption based on Shapley value [J]. Energy Engineering, 2012, 6: 5-12. 